breathing. Pediatrics March 2000;109:449-456). (Respond: Ronald D Chervin MD MS, Michael S Aldrich Sleep Disorders Laboratory, 8D8702 University Hospital, Box 0117, 1500 E Medical Center Dr, Ann Arbor, MI 48109).

COMMENT. Inattention and hyperactive behavior, cardinal symptoms of ADHD, may be associated with increased daytime sleepiness, snoring and other symptoms of sleep-disordered breathing. Daytime sleepiness is linked to hyperactive behavior in boys and girls of all ages, whereas the association of snoring and behavior is limited to boys under 8 years of age. Questions regarding sleep habits and snoring are important in the evaluation of children with symptoms of ADHD. A possible causal relationship needs further study.

The causes of sleep problems in children with ADHD include stimulant medications, anxiety disorder, and environmental behavioral sleep deprivation (Trommer BL, et al. Ann Neurol 1988;24:322). Objective measurements of sleep habits, such as polysomnography and actigraphy, have shown conflicting results, while parental ratings reveal an increased prevalence of sleep problems in children with ADHD. The child's own perspective of sleep habits correlate with those of the parents ( see Ped Neur Briefs June 2000;14:47). If upper airway obstruction is excluded as a cause of snoring and sleep-disordered breathing, the substitution of clonidine for stimulant medication should be considered in ADHD children.

\title{
STIMULANT EFFECTS ON AGGRESSIVE BEHAVIOR AND ADHD
}

The effect of stimulants on overt (physical assault or temper outburst) and covert (cheating, lying, stealing, vandalism) aggression-related behaviors in children with ADHD was determined by literature meta-analysis at the University of Massachusetts Medical School and Northeastern University, Boston. A review of 28 published reports, 1970-2001, revealed 28 and 7 independent effects of overt and covert aggression, respectively. Stimulants had significant, moderate to large effects on aggression-related behaviors, separate from and of equal magnitude to their effects on symptoms of ADHD. Girls responded equally as well as boys. Dose had no significant relation to effect size, but duration of treatment had a significant positive correlation. (Connor DF, Glatt SJ, Lopez ID, Jachson D, Melloni $\mathrm{RH}$ Jr. Psychopharmacology and aggression. I: A meta-analysis of stimulant effects on overt/covert aggression-related behaviors in ADHD. LAm Acad Child Adolesc Psychiatry March 2002;41:253-261). (Reprints: Dr Connor, Department of Psychiatry, 7 th Floor, Room S7-850, University of Massachusetts Medical School, 55 Lake Ave, North, Worcester, MA 01655).

COMMENT. Treatment with stimulants is effective in the control of aggressive-related behaviors in children with ADHD and co-morbid conduct disorders.

Psychiatric comorbidity in preschool children with ADHD. In a study of 165 patients aged 4 to 6 years compared to 381 aged 7 to 9 years, the preschoolers had similar substantial rates of impairment in school, social, and overall functioning to those in school-age children. (Wilens TE, Biederman J, Brown S et al. Psychiatric comorbidity and functioning in clinically referred preschool children and school-age youths with ADHD. I Am Acad Child Adolesc Psychiatry March 2002;41:262-268). These findings support an early intervention treatment program for preschoolers presenting with ADHD. 